Commentary

\title{
The time for National Colorectal Cancer Screening Program
}

Hend Samir Ali

A resident of Internal Medicine at Belbeis Hospital, M.B.B.CH Zagazig University

Received: 22 October 2021; Accepted: 25 October 2021; Published: 27 October 2021.

*Correspondence: Hend Samir Ali.

Email: eyes.ofpain@yahoo.com, drhendabozeid@gmail.com

Sharkia, Zagazig.

DOI: https://doi.org/10.52378/yms

Cell phone: $+\mathbf{2 0 1 2 8 5 0 4 2 5 2 2}$

\section{Abstract}

There are no current screening or surveillance guidelines for CRC in Egypt, and most of the individual screening is scarcely done. Consequently, many cases of CRC are diagnosed in a late stage. Hence, we are in a natural and urgent need to formulate Egyptian guidelines that suites our population, our physicians and compel with our limited health resources. If developed and implemented, these guidelines will help detect early stages of CRC, reduce cancer-related treatment expenses, and improve the prognosis.

The awareness of both the public and the physicians about this preventable cancer needs enhancements.

Keywords: national, screening, guidelines, Colorectal cancer, awareness.

Colon cancer ranks $3^{\text {rd }}$ among all cancers globally, ranking $2^{\text {nd }}$ regarding cancer-related death (1). In Egypt no accurate formal prevalence rates; however, early reports showed that colorectal cancer is the $7^{\text {th }}$ commonest cancer among Egyptians (2). From the practice point of view, colon cancer is prevalent among different age groups of Egyptians, and no age seems immune against the development of this cancer.

The prognosis of colon cancer seems good if diagnosed early. The overall 5-year survival rate is $63 \%$, and if the cancer is diagnosed at a localized stage, the survival rate is $91 \%$ (3). Furthermore, it is classified as preventable cancer (4) because many predisposing factors can be identified and managed (5). Among the many risk factors are inflammatory bowel diseases, family history of colon cancer, and that is why the current practice guidelines favored screening not only the general population but further these high-risk groups aiming at the detection of the early pathological lesions of CRC (6), offering endoscopic management of such lesions and offer to follow up (7) which ultimately reduces the probability of invasive cancer.

There is compelling evidence to support screening average-risk individuals over age 50 years to detect and prevent CRC. Screening of average-risk individuals can reduce CRC mortality by detecting cancer at an early, curable stage and detecting and removing clinically significant adenomas. No CRC screening test is perfect for cancer detection or adenoma detection. Each test has unique advantages, is cost-effective, and has associated limitations and risks. Patient preferences and the availability of resources play an essential role in selecting screening tests. 
Colorectal cancer screening programs remain less prevalent because of the invasive nature of endoscopies, financial burden, lack of a commonly accepted method of screening by researchers, and other barriers to screening. However, medical experts and researchers agree that given an incidence of 1.36 million new cases annually, there exists a significant need for the implementation of more systematic screening programs (8), and that is why the American Cancer Society believes that all people should benefit from cancer screenings, without regard to health insurance coverage.

It became mandatory to highlight the need for and impact of colorectal cancer screening programs by highlighting the correlation between the implementation of systematic colorectal cancer screening programs the decrease in incidence and mortality of colorectal cancer (9).

Furthermore, the health systems must evaluate the components and characteristics of population-based colorectal cancer screening programs, which prove effective in reducing the incidence and mortality rate of colorectal cancer in a population, and evaluate features and components of successful screening programs to establish recommended guidelines in designing such programs (8).

The majority of colorectal cancer screening programs deliver testing on a routine basis (systematic), take into account population demographics (population-based), and are implemented by the federal government (national) (9).

Researchers estimate that more than one in three people will develop some cancer. In the United Kingdom, for example, in 2010, one in 13.7 men developed colorectal cancer and one in 17.8 women. According to this data, researchers predicted by 2030, men in the United Kingdom will have an eight percent risk of developing colorectal cancer in their lifetime, and women will have a seven percent risk. The risk of developing colorectal cancer continues to steadily increase from the first census taken by the Cancer Research UK in 1975(10).

These statistics represent the risk presented to the general population of the United Kingdom but give a good representation of the known risk, however as with all diseases, some folks have a higher risk than others. Lifestyle habits and personal characteristics subject certain people to a higher risk of developing colorectal cancer than others (8).

Recently, a group of Egyptian medical students published a minireview about screening guidelines of CRC, figuring out the delays in diagnosis and management of CRC. Such structured activities can increase awareness about CRC screening among medical students even before starting their clinical careers (11).

There is a need to educate young physicians about premalignant conditions and the benefits of early detection of CRC. A recently published mini-review by a group of Egyptian students (11) targeting the status of CRC in Egypt showed that a remarkable delay in diagnosis of CRC is present. Such activities for a physician in their early career increase CRC awareness. Furthermore, teaching the practice guidelines improves its implementation and positively affects the outcomes (12). On the other hand, understanding the public is highly appreciated. In a recent study, through a questionnaire focusing on the first-degree relatives of Egyptian CRC patients, investigators found that all the surveyed relatives refused the screening tests, even the non-invasive ones (13). The rationale for this, according to the survey, was cultural. Most of them said we are healthy looking and have no symptoms, so why do I investigate? We believe that this is the most critical individual-related barrier -among others- against CRC screening. This can be solved by running mass awareness campaigns like the successful one during the mass treatment of HCV. The public needs to be convinced to be recruited in the available screening guidelines. Furthermore, 
the fear of the people from invasive investigations, e.g., endoscopy, should be solved by searching for other non-invasive screening tools accepted by the individuals.

\section{Footnotes.}

Citation of this article: Ali $H$ S. The time for National Colorectal Cancer Screening Program. African journal of gastroenterology and hepatology [Internet]. Egypt's Presidential Specialized Council for Education and Scientific Research; 2021 Oct 27;4(1):29-32. Available from: http://dx.doi.org/10.52378/yms.

Peer- Reviewers: Mohamed Hassan Ali Emara (professor of hepatology, gastroenterology, and infectious diseases), Emad Fawzi Hamed (professor of internal medicine), prof Hanan Soliman (tropical medicine, Tanta University), prof Nahed Hussien (parasitology department, Zagazig University).

E- Editor: Salem Y Mohamed.

Copyright (C). This open-access article is distributed under the Creative Commons Attribution License (CC BY). The use, distribution, or reproduction in other forums is permitted, provided the original author(s) and the copyright owner(s) are credited. The original publication in this journal is cited by accepted academic practice. No use, distribution, or reproduction is permitted, which does not comply with these terms.

Disclaimer: All claims expressed in this article are solely those of the authors and do not necessarily represent their affiliated organizations or those of the publisher, the editors, and the reviewers. Any product evaluated in this article or claim that its manufacturer may make is not guaranteed or endorsed by the publisher.

\section{References:}

1. Ferlay J, Ervik M, Lam F, Colombet M, Mery L, Piñeros M, et al. Global Cancer Observatory: Cancer Today. Lyon: International Agency for Research on Cancer; 2020 (https://gco.iarc.fr/today, accessed February 202.

2. Ibrahim AS, Khaled HM, Mikhail NN, Baraka H, Kamel H. Cancer incidence in Egypt: results of the national population-based cancer registry program. J Cancer Epidemiol. 2014; 2014:437971).

3. Swanson RS, Compton CC, Stewart AK, Bland KI. The prognosis of T3N0 colon cancer is dependent on the number of lymph nodes examined. Ann Surg Oncol. 2003 Jan-Feb;10(1):65-71. doi: 10.1245/aso.2003.03.058. PMID: 12513963.

4. Gorman C. Katie's crusade. Colon cancer is one of the deadliest and most preventable malignancies. What you need to know about the disease--and the surprisingly painless test that could save your life. Time. 2000 Mar 13;155(10):70-6. PMID: 11009699.

5. Giovannucci E. Modifiable risk factors for colon cancer. Gastroenterol Clin North Am. 2002 Dec;31(4):925-43. doi: 10.1016/s0889-8553(02)00057-2. PMID: 12489270.

6. Smith RA, Andrews KS, Brooks D, Fedewa SA, Manassaram-Baptiste D, Saslow D, Wender RC. Cancer screening in the United States, 2019: A review of current American Cancer Society guidelines and current issues in cancer screening. CA Cancer J Clin. 2019 May;69(3):184-210. doi: 10.3322/caac.21557. Epub 2019 Mar 15. PMID: 30875085.

7. Kaltenbach T, Anderson JC, Burke CA, Dominitz JA, Gupta S, Lieberman D, Robertson DJ, Shaukat A, Syngal S, Rex DK. Endoscopic Removal of Colorectal Lesions-Recommendations by the US Multi-Society Task Force on Colorectal 
Cancer. Gastrointest Endosc. 2020 Mar;91(3):486-519. doi:

10.1016/j.gie.2020.01.029. Epub 2020 Feb 14. PMID: 32067745.

8. Onyoh EF, Hsu WF, Chang LC et al. (2019). The rise of colorectal cancer in Asia: epidemiology, screening, and management. Current gastroenterology reports, 21(8), 36.

9. Levin TR, Corley DA, Jensen et al. (2018). Effects of organized colorectal cancer screening on cancer incidence and mortality in a large community-based population. Gastroenterology, 155(5), 1383-1391.

10. American Cancer Society. "Colorectal cancer facts \& figures 2020-2022."

Published online (2020): 48.

11. Zaki MM, said MAA, Mohamed MMA, abdelrasheed MF, Adel M, Farag MM, et al. Colorectal cancer screening: a minireview. African journal of gastroenterology and hepatology [Internet]. Egypt's Presidential Specialized Council for Education and Scientific Research; 2019 Aug 6;2(1):65-73. Available from:

http://dx.doi.org/10.52378/hsym8873.

12. Opadeyi AO, Fourrier-Réglat A, Isah AO. An educational intervention to improve healthcare professionals' knowledge, attitude, and

practice regarding pharmacovigilance in South-South Nigeria. Ther Adv Drug Saf. 2019 Jan 25; 10:2042098618816279.

13. Elsayed AF, Ali HS, El-Maghawry HA, Atia H, Mohamed SY. Compliance of Blood Relatives of Colorectal Cancer Patients to Colorectal Screening Guidelines. J Gastrointest Cancer. 2021 Nov 10. doi: 10.1007/s12029-021-00756-1. Epub ahead of print. PMID: 34761339. 